Rozhelyuk Viktoriya,

$P h D$ in Economics, assistant professor of the department of accounting in state economic sector and human services, Ternopil National Economic University

\title{
RESEARCH COMPETENCE ACCOUNTING PROFESSION AS A SPECIALST BUSINESS PROCESS MANAGEMENT IN PROCESSING INDUSTRIES
}

The article is the realization of research competence accountancy profession as a specialist business process management in processing industries.

The main base for the study are research scientists to research the accounting profession as a specialist business process management in processing industries. When writing articles used methods: monographic (the study of scientific publications of scientists for the development of basic principles of formation of accounting in the processing industry), theoretical synthesis method (with a theoretical analysis of the basic job requirements, principles and requirements of operation chief accountant).

Research results. The stages of requirements for the operation positions of chief accountant and financial director. The characteristic advantages of the profession. The author systematized the basic job requirements for the accountancy profession.

Scientific novelty of research results is the main justification for the development of research results and formation vysokvalifikovanoho and competent accountant - expert in domestic processing industries.

The practical significance of the study. The results in the paper is the basis for solving scientific and theoretical issues related to improving professional competence problems accountant.

Keywords: requirements for the operation positions of chief accountant and CFO; accounting profession; processing industries; management of business - processes at enterprises; job requirements; principles of ethical behavior accountant.

(C) Рожелюк Вікторія

Надійшла до редакції 18.05.2015

УДК 658.5

САДОВА МАРІЯ,

здобувач Свропейського університету, м. Київ

\section{РОЗРОБКА СИСТЕМИ КОНТРОЛЮ ЯКОСТІ НАДАННЯ ДОРОЖНЬО-БУДІВЕЛЬНИХ ПОСЛУГ}

У статті запропонований підхід до розробки комплексної системи контролю якості надання дорожньо-будівельних послуг, який базується на моделі формування взаємозв'язку конструктивних, технологічних та організаційних параметрів дорожніх робіт. Модель дозволяє проаналізувати контрольні параметри на стадії виробництва й оцінити їх вплив на якість та надійність об'єкта дорожнього будівництва на відповідній стадії експлуатації, що дає можливість комплексного контролю якості проведення окремих видів дорожніх робіт; якості матеріалів, що використовуються в дорожньому будівництві; підготовки та прийняття конструктивно-технологічних та організаційних рішень під час проведення дорожньо-будівельних робіт.

Ключові слова: підприємство; дорожньо-будівельні послуги; підхід; система контролю якості.

Постанова проблеми. Стан дорожнього господарства має сьогодні стратегічне значення для відродження й розвитку макроекономічних зв'язків між регіонами України та іншими країнами. Кількість і якість транспортних комунікацій - це показник науково-технічного й економічного розвитку країни, задовільне значення якого покликаний забезпечити дорожньо-будівельний комплекс. Сучасні економічні умови характеризуються високими темпами розвитку ринкових відносин, інтеграційних процесів, у тому числі міжнародних, що перед- бачає зростання рівня конкуренції в провідних галузях економіки, до яких відноситься будівництво, зокрема, дорожнє будівництво [1-3].

У сфері дорожнього будівництва конкуренція проявляється під час проведення підрядних торгів на проектування дороги, поставку та виробництво матеріалів, робіт і послуг на її будівництво, інших робіт, які, зокрема, забезпечують дотримання проектних показників і нормативів у процесі будівництва й реконструкції, а також робіт і послуг, пов'язаних з ефективним і якісним 
обслуговуванням дороги на стадії ії експлуатації. Державна політика в галузі дорожнього будівництва дозволяє говорити про очікуване підвищення інвестиційної привабливості його об'єктів, у тому числі для іноземних підрядників, що загострює проблему посилення конкурентоспроможності вітчизняних підприємств визначає необхідність підвищення економічної ефективності їхньої діяльності та якості виконуваних робіт і послуг як основних чинників конкурентоспроможності [5].

Аналіз останніх досліджень та публікацій. Існує достатня кількість робіт з економіки будівництва транспортної інфраструктури. Зокрема, Г. Бірман, Ц. Шмідт, А. Васіна, М. Грашина, Є. Дубінін, Б. Сазонов, 3. Черняк, К. Фрідман, К. Крістенсен провели детальні дослідження процесу управління такими проектами. Однак деякі аспекти цієї категорії залишаються недостатньо вивченими

Метою роботи $є$ розробка комплексної системи контролю якості дорожнього будівництва та визначення методичного підходу до неї.

Виклад основного матеріалу. Якість дорожніх робіт на об'єктах забезпечують робочі, бригадири, майстри та виробники робіт. Їхній обов'язок - забезпечення якості робіт відповідно до проектів проведення робіт, робочих креслень і технічних умов на виконання й приймання робіт. Якість окремих видів робіт, у тому числі прихованих, конструктивних елементів споруд, підлягає обов'язковій оцінці при проміжному прийнятті, а якість закінчених об'єктів - при здаванні [4].

У зв'язку із цим, контроль якості за проведенням дорожніх робіт пропонується проводити на основі використання доповненої автором існуючої методики оцінки якості дорожньо-будівельних робіт [2]. Доповнений автором підхід передбачає проведення контролю якості на етапах здійснення окремих видів дорожніх робіт, контролю якості матеріалів, що використовуються, та контролю за прийняттям конструктивних та організаційно-технологічних рішень.

1. Оцінка якості влаштування земляного полотна:

$$
\begin{aligned}
& S=\frac{k_{1} P_{1}+k_{2} P_{2}+k_{3} P_{3}+k_{4} P_{4}+k_{5} P_{5}}{k_{1}+k_{2}+k_{3}+k_{4}+k_{5}}, \\
& k_{1}=0,7 ; k_{2}=1,0 ; k_{3}=0,8 ; k_{4}=0,6 ; k_{5}=0,7
\end{aligned}
$$

де:

$P_{1}$ - оцінка якості підготовки основи земляного полотна;

$P_{2}$ - оцінка якості зведення насипів і розробки виїмок;

$P_{3}$ - оцінка якості влаштування водовідведення;

$P_{4}$ - оцінка якості створення присипного узбіччя;

$P_{5}$ - оцінка якості проведення укріплювальних робіт.

2. Оцінка якості будівництва дорожніх основ і покриттів:

$$
S_{r}=\frac{5 \times W_{1}+4 \times W_{2}+3 \times W_{3}}{W_{1}+W_{2}+W_{3}}
$$

де:

$S_{r}$ - показник якості окремих ділянок, побудованих у різний час або в різних місцях;
$W_{1}$ - протяжність прийнятих ділянок дорожніх основ або покриттів, що були оцінені експертами на "відмінно";

$W_{2}$ - протяжність прийнятих ділянок дорожніх основ або покриттів, що отримали оцінку експертів "добре";

$W_{3}$ - протяжність прийнятих ділянок дорожніх основ або покриттів, що були оцінені експертами на "задовільно".

3. Оцінка якості будівельно-монтажних робіт закінченого будівництва ділянки дороги:

$$
\begin{aligned}
& S_{f}=\frac{k_{1} G_{1}+k_{2} G_{2}+k_{3} G_{3}+k_{4} G_{4}+k_{5} G_{5}+k_{6} G_{6}+k_{7} G_{7}}{k_{1}+k_{2}+k_{3}+k_{4}+k_{5}+k_{6}+k_{7}} ; \\
& k_{1}=0,5 ; k_{2}=1,0 ; k_{3}=0,9 ; k_{4}=0,9 ; k_{5}=0,9 ; k_{6}=0,6 ; k_{7}=0,7
\end{aligned}
$$

де:

$G_{1}$ - оцінка якості підготовчих робіт;

$G_{2}$ - оцінка якості влаштування земляного полотна;

$G_{3}$ - оцінка якості зведення штучних споруд;

$G_{4}$ - оцінка якості влаштування основи дорожнього покриття;

$G_{5}$ - оцінка якості влаштування дорожніх покриттів;

$G_{6}$ - оцінка якості зведення будівель і споруд дорожньої й автотранспортної служби;

$G_{7}$ - оцінка якості облаштування дороги дорожніми приладами на ділянці, що здається.

4. Оцінка якості дорожньо-будівельних робіт підприємства за визначений період часу (місяць, квартал, рік):

$$
C=\frac{5 \times V_{1}+4 \times V_{2}+3 \times V_{3}}{V_{1}+V_{2}+V_{3}}
$$

де:

C - оцінка якості будівельно-монтажних робіт підприємства за визначений період часу;

$V_{1}$ - оцінка якості виконаного обсягу дорожньо-будівельних робіт на "відмінно";

$V_{2}$ - оцінка якості виконаного обсягу дорожньо-будівельних робіт на "добре";

$V_{3}$ - оцінка якості виконаного обсягу дорожньо-будівельних робіт на "задовільно".

На основі отриманих розрахункових результатів оцінки якості здійснення окремих видів дорожніх робіт, проводиться осереднення контрольованих показників якості, які заносяться до контрольної карти (рис. 1).

Щодо контролю якості матеріалів, що використовуються підприємством у процесі проведення дорожньо-будівельних робіт, то припустімо, що існує деякий гранично допустимий рівень матеріалів низької якості $l_{b}$ у загальній сукупності матеріалів, які використовуються в процесі виконання дорожньо-будівельних робіт:

$$
l_{b}=\frac{D_{b}}{N}
$$

де:

$D_{b}$ - гранично допустима кількість матеріалів низької якості;

$N$ - загальна кількість матеріалів. 


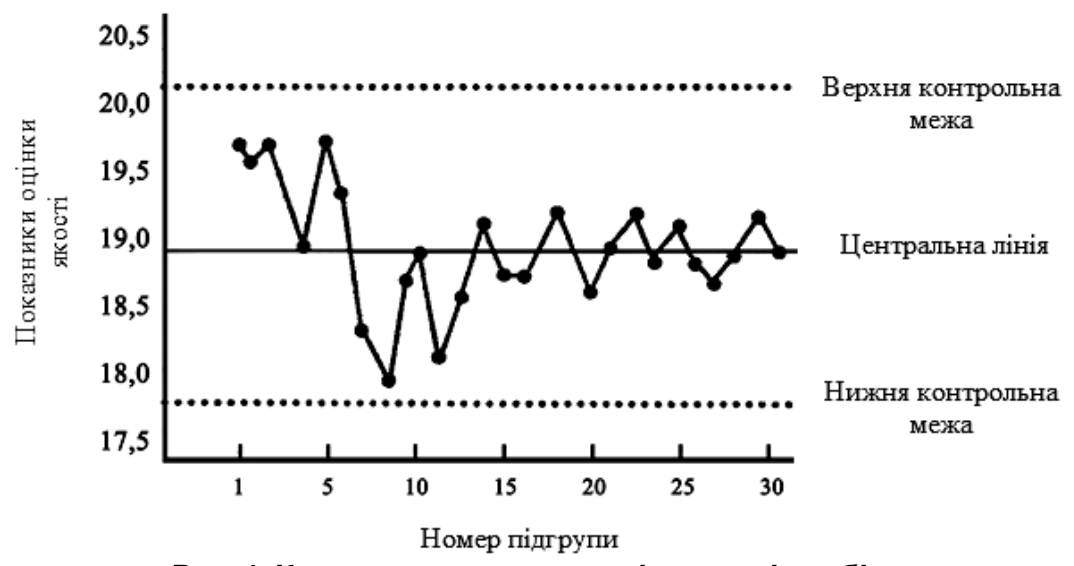

Рис. 1. Контрольна карта якості дорожніх робіт.

Гранично допустимий рівень матеріалів низької якості буде постійно знижуватися, оскільки вимоги до якості постійно зростають.

Обсяг дорожньо-будівельних матеріалів, що у своїй сукупності має матеріали низької якості, має вважатися прийнятним до використання, якщо $l \leq l_{b}$, та неприйнятним до використання, якщо $l \mathrm{f} l_{b}$.

Представимо сукупність дорожньо-будівельних матеріалів у вигляді деякої множини $\left\{a_{1}, a_{2}, \mathrm{~K} a_{i}, \mathrm{~K} a_{N}\right\}$, кожен елемент якої може відповідати як задовільному рівню якості, так і незадовільному. Для моделювання процесу контролю зв'яжемо з кожним елементом такої множини значення деякої функції непридатності (браку) $E_{i}$. Якщо $i$-й елемент не придатний, то $E_{i}=1$, а якщо елемент придатний, то $E_{i}=0$. Для моделювання сукупності дорожньо-будівельних матеріалів, що містить $D$ матеріалів низької якості, величина засміченості браком буде дорівнювати:

$$
l=\frac{D}{N}
$$

На основі представленої моделі контролю гранично допустимого рівня якості матеріалів, що використовуються при проведенні підприємством дорожньо-будівельних робіт, пропонується схема контролю якості матеріалів, представлена на рис. 2.

У зв'язку з тим, що на стадіях проектування, здійснення дорожніх робіт та експлуатації безперервно змінюються інженерно-геологічні, кліматичні, ґрунтові характеристики, також необхідно проводити контроль за конструктивними та організаційно-технологічними рішеннями. Вирішення цього завдання із системотехнічних позицій засноване на постійному контролі характеристик з метою визначення їх спільного впливу на результуючі показники: термін здавання дорожнього об'єкта, відкриття тимчасової експлуатації, темпи й вартість робіт.

Методичні етапи вирішення задачі в такій постановці наведені в табл. 1 .

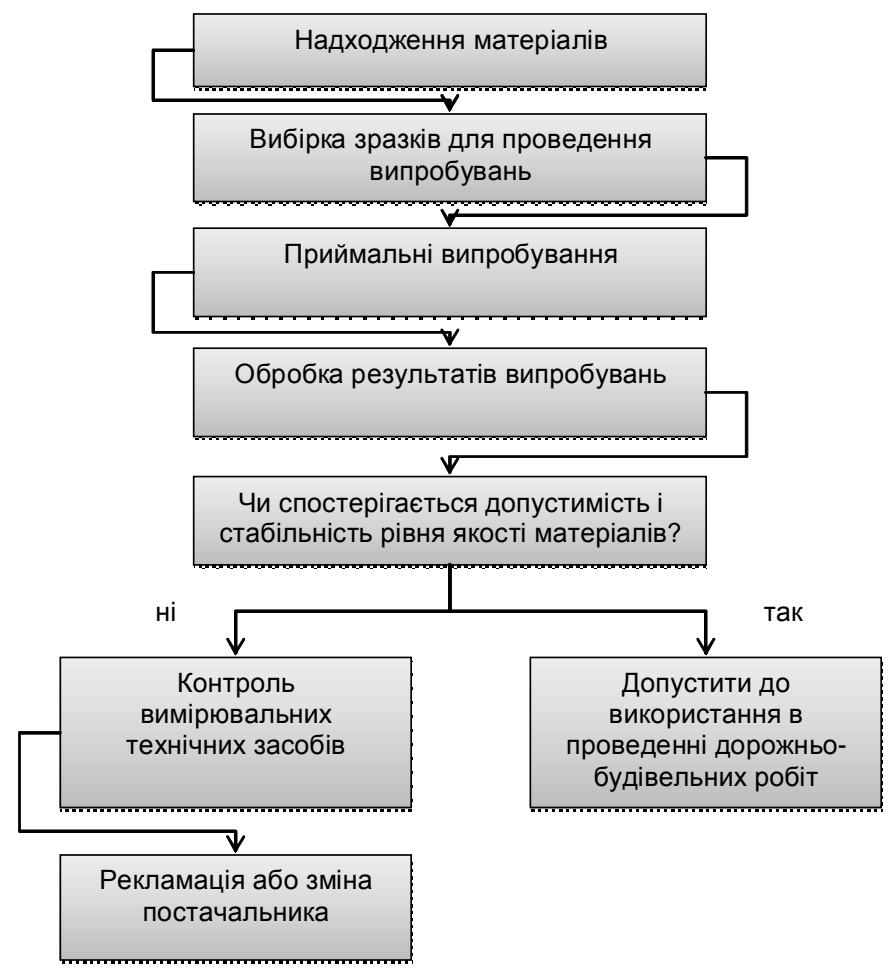

Рис. 2. Процес контролю якості дорожньо-будівельних матеріалів. 
Таблиця 1. - Контроль підготовки та прийняття конструктивно-технологічних та організаційних рішень під час проведення дорожньо-будівельних робіт

\begin{tabular}{|l|l|}
\hline & \multicolumn{1}{|c|}{ Конструктивно-технологічні та організаційні рішення } \\
\hline 1 & Визначення складу та обсягів робіт по технологічних процесах у базовому варіанті конструкції \\
\hline 2 & Розрахунок фондів машиноресурсів, продуктивності й тривалості процесів дорожніх робіт \\
\hline 3 & Календарний граффік виконання робіт на ділянці, визначення терміну виконання комплексу робіт \\
\hline 4 & Визначення результуючих показників - вартості й термінів здачі об'єктів дорожнього будівництва \\
\hline 5 & Корегування базового варіанту конструкції й обсягів робіт залежно від сезону виробництва дорожніх робіт \\
\hline 6 & Регулювання технологічних процесів у взаємозв'язку з прийнятим варіантом конструкції земляного полотна \\
\hline
\end{tabular}

Алгоритм взаємозв'язку параметрів заснований на розрахунку комплексної характеристики - термінів виробництва дорожніх робіт і здачі об'єкта будівництва:

$$
T=\frac{\sum Q_{i j}}{N_{i} \cdot P_{i j} \cdot F_{i}} \cdot f_{t}\left(V_{i j}\right) \cdot F_{t}(R)
$$

де:

$Q_{i j}$ - обсяг робіт $i$-го виконавця на $j$-ій ділянці будівництва;

$N_{i}$ - загальна кількість виконавців (будівельних машин, бригад) на ділянці;

$P_{i j}, F_{i}$ - продуктивність та фронд робочого часу машин;

$R$ - технологічні характеристики об'єкта.

Таким чином, розроблена модель взаємозв'язку конструктивних, технологічних та організаційних параметрів дорожніх робіт. На її основі створено алгоритм розрахунку, який дозволяє аналізувати взаємозв'язок перерахованих контрольних параметрів на стадії виробництва робіт й оцінювати їх вплив на якість та надійність об'єкта дорожнього будівництва на стадії його експлуатації.

\section{Висновки}

Запропоновано методичний підхід до розробки комплексної системи контролю якості за дорожнім будівництвом, який включає:
- контроль якості проведення окремих видів дорожніх робіт (на основі вдосконаленої методики оцінки якості);

- контроль якості матеріалів, що використовуються в дорожньому будівництві (на основі запропонованої економіко-математичної моделі визначення гранично допустимого рівня матеріалів низької якості);

- контроль підготовки та прийняття конструктивнотехнологічних та організаційних рішень під час проведення дорожньо-будівельних робіт (на основі запропонованої моделі взаємозв'язку конструктивних, технологічних та організаційних параметрів дорожніх робіт).

\section{ЛІТЕРАТУРА}

1. Коуден Д. Статистические методы контроля качества / Д. Коуден ; [под ред. Б. Р. Левина]. - М. : Физматгиз, 2001. C. $192-195$.

2. Балановська Т. І. Сучасні й класичні методи управління якістю: особливості та перспективи застосування [Електронний ресурс] / Т. І. Балановська. - Режим доступу : http:// archive.nbuv.gov.ua/portal/soc_gum/nvnau_eamb/2012_169_1/ 12bti.pdf.

3. Харченко Т. Б. Якість продукції в системі факторів конкурентоспроможності підприємства : дис. ... канд. екон. наук : 08.00.05 / Т. Б. Харченко. - К., 2006. - 220 с.

4. Shewhart W. A. Statistical method from the viewpoint of quality control / W. A. Shewhart. - Washington : The Department of Agriculture, 1999. - Рp. 150-155.

5. Исикава К. Японские методы управления качеством / к. Исикава. - М. : Экономика, 2001. - С. 320-329.

Садова Мария,

соискатель Европейского университета, г. Киев

\section{РАЗРАБОТКА СИСТЕМЫ КОНТРОЛЯ КАЧЕСТВА ПРЕДОСТАВЛЕНИЯ ДОРОЖНО-СТРОИТЕЛЬНЫХУСЛУГ}

В статье предложен подход к разработке комплексной системы контроля качества предоставления дорожно-строительных услуг, основанный на модели формирования взаимосвязи конструктивных, технологических и организационных параметров дорожных работ. Модель позволяет проанализировать контрольные параметры на стадии производства и оценить их влияние на качество и надежность объекта дорожного строительства на соответствующей стадии эксплуатации, что дает возможность комплексного контроля качества проведения отдельных видов дорожных работ; материалов, используемых в дорожном строительстве; подготовки и принятия конструктивно-технологических и организационных решений при проведении дорожно-строительных работ.

Ключевые слова: предприятие; дорожно-строительные услуги; подход; система контроля качества.

Sadova Mariia,

aspirant of the European University, Kyiv

\section{THE DEVELOPMENT OF QUALITY CONTROLSYSTEM PROVIDING ROAD-BUILDING SERVICES}

Determined that the effectiveness of the management of enterprise road construction, largely determined by the quality of road works. Over the past $\mathbf{1 5}$ years in the industry made a lot of work to improve quality control system, which was due to a change in the economic model of the national economy. A great amount of work on 
a mechanism of quality control, based on compliance with existing regulations and design documentation. This could substantially improve the quality of road works to reduce the number of deviations from the requirements. However, if you switch from road works quality indicators to the indicators of the state of the road network, it must be noted that the volume of outstanding problems in recent years is growing. An approach to the development of a comprehensive quality control system of road-construction services, based on the model of the formation of the relationship of constructive, technological and organizational parameters of road works, which analyzes the control parameters listed in the production stage and assess their impact on the quality and reliability of road construction at an appropriate stage operation, which enables integrated control: the quality of the individual types of road works; materials used in road construction; preparation and adoption of constructive-technological and organizational decisions during the road construction.

Keywords: enterprise; road-construction services; approach; quality control system.

\section{REFERENCES}

1. Cowden D. (2001), Statistical methods for quality control, Moscow, pp. 192-195 (rus).

2. Balanovska T. I. (2012), Modern and classic quality control methods, features and application prospects, available at: http:// archive.nbuv.gov.ua/portal/soc_gum/nvnau_eamb/2012_169_1/12bti.pdf (ukr).

3. Kharchenko T. B. (2006), Product quality in the competitiveness of the enterprise, Thesis for the degree of the candidate of economic sciences in specialty 08.00.05 "The development of productive forces and regional economy", Kyiv, 220 p. (ukr).

4. Shewhart W. A. (1999), Statistical method from the viewpoint of quality control, The Graduate School, the Department of Agriculture, Washington, pp. 150-155 (engl).

5. Ishikawa K. (2001), Japan quality control methods, Economics, Moscow, pp. 320-329 (rus).

(C) Садова Марія

Надійшла до редакції 13.07.2015

Удк 005.591.4:622.012.2:004

САПИЦЬКА ІРИНА, кандидат технічних наук, доцент Донецького начіонального університету, м. Вінниия

\section{РЕСТРУКТУРИЗАЦІЯ ВУГІЛЬНИХ ШАХТ: ІНФОРМАЦІЙНІ РЕСУРСИ}

\footnotetext{
У статті охарактеризований сучасний стан вугільних шахт Донбасу, виконано його оцінку. Актуалізовано формування перспективних планів реструктуризації галузі з огляду на важливість цього стратегічного ресурсу для національної економіки. Показано, що важливим елементом у процесі реалізації технологічних змін $\epsilon$ інформаційні ресурси. Визначені основні напрями автоматизації на вугільних підприємствах: технологічний та управлінський. У технологічному аспекті приділена увага системам АIC, УТАС, ITPAC; в управлінському - СКІП. Для підвищення якості праці запропоновано використати окремі модулі геоінформаційної системи "САМАРА", а також програмного продукту "1С : Підприємство".
}

Ключові слова: реструктуризація; шахти; технологічні зміни; автоматизація; інфрормаційні ресурси; геоінформаційні системи; програмний продукт.

Постановка проблеми. У час проведення АТО вугільна промисловість Донбасу переживає дуже складний період. Більшість шахт працює зі зниженою продуктивністю, або й зовсім простоює. У зв'язку із цим видобуток постійно змінюється (рис. 1).

Вугілля для України є стратегічним ресурсом, тому, незважаючи на теперішні труднощі, треба фрормувати плани на майбутнє. Важливу роль у покращенні показників діяльності шахт відіграє реструктуризація.

Автором цієї статті у попередній публікації була запропонована модель реструктуризації, що містить технологічні зміни, важливим елементом яких $є$ інформаційні ресурси [12].

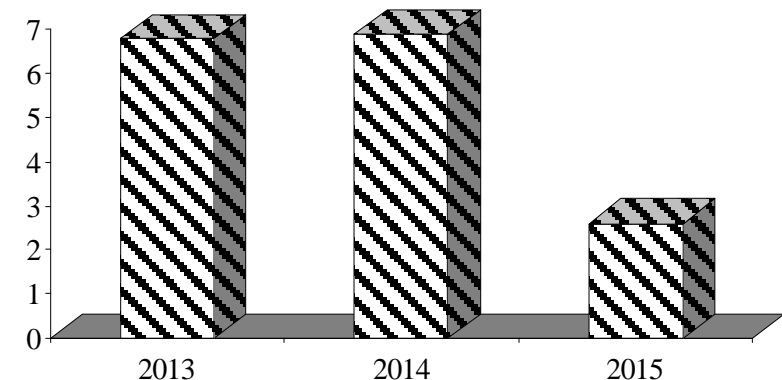

Рис. 1. Динаміка видобутку вугілля в Україні за січень 2013-2015 рр., млн т [6, 7]. 